\title{
Reduced tumorigenicity and drug resistance through the downregulation of octamer-binding protein 4 and Nanog transcriptional factor expression in human breast stem cells
}

\author{
ZHENG-JIE HUANG ${ }^{1,2^{*}}$, JUN YOU ${ }^{1 *}$, WEI-YUAN LUO ${ }^{1}$, BAI-SHENG CHEN ${ }^{1,2}$, \\ QING-ZHAO FENG ${ }^{1}$, BING-LIN WU ${ }^{1,2}$, LONG JIANG $^{1,2}$ and QI LUO ${ }^{1,2}$ \\ ${ }^{1}$ Department of Surgical Oncology, The First Affiliated Hospital of Xiamen University, Xiamen, Fujian 361003; \\ ${ }^{2}$ Department of Surgical Oncology, First Clinical Medical College of Fujian Medical University, \\ Fuzhou, Fujian 350004, P.R. China
}

Received December 27, 2013; Accepted October 20, 2014

DOI: $10.3892 / \mathrm{mmr} .2014 .2972$

\begin{abstract}
Breast cancer is the most common type of malignancy among females. Previous studies examining breast cancer tissue have demonstrated the presence of stem cells, and have detected octamer-binding protein 4 (Oct4) and Nanog transcription factor expression. In the present study, breast cancer stem cells (CSCs) were isolated and enriched from MDA-MB-231 breast cancer cell lines, and were defined as MDA-MB-231 stem cells using flow cytometry. The expression of Oct 4 and Nanog in breast CSCs were detected by quantitative polymerase chain reaction and western blotting. RNA interference (RNAi) was used in order to downregulate the expression of Oct4 and Nanog. Drug resistance and tumor-initiating capability following in vivo injection of MDA-MB-231 stem cells transduced with negative RNAi, Oct4 RNAi and Nanog RNAi were compared with that of MDA-MB-231 stem cells without siRNA transfection as a control group. In addition the capability of MDA-MB-231 breast cancer cells to initiate tumor formation in mice was compared with that of MDA-MB-231 stem cells. A paclitaxel inhibition test was also conducted in order to detect resistance of MDA-MB-231 breast cancer stem cells to this treatment. The MDA-MB-231 stem cells were revealed to exhibit elevated percentages of the cluster of differentiation (CD) $44^{+} \mathrm{CD} 24^{-/ \text {low }}$ subset, high tumorigenicity and resistance to chemotherapy, all of which are characteristic stem cell properties. In addition, the MDA-MB-231 stem cells were more tumorigenic in vivo. Furthermore, the breast CSCs also expressed high levels of the Oct4 and Nanog transcription factors. Therefore,
\end{abstract}

Correspondence to: Dr Qi Luo, Department of Surgical Oncology, The First Affiliated Hospital of Xiamen University, 55 Zhen Hai Road, Xiamen, Fujian 361003, P.R. China

E-mail: luoqixmzsh@126.com

${ }^{*}$ Contributed equally

Key words: breast cancer stem cells, isolation and identification, octamer-binding protein 4, Nanog, tumorigenicity, drug resistance downregulation of Oct4 or Nanog expression may reduce chemotherapeutic drug resistance and tumorigenicity in breast CSCs. In conclusion, Oct4 and Nanog expression may be a key factor in the development of resistance to chemotherapy and tumor growth of breast CSCs. This finding indicates that Oct 4 or Nanog-targeted therapy may be a promising means of overcoming resistance to chemotherapy and inhibiting tumor growth in breast cancer treatment.

\section{Introduction}

In recent years, there has been an increasing focus on the cancer stem cell (CSC) hypothesis. This hypothesis identifies a small subset of cancer cells that constitute the bulk of self-sustaining cells with a unique capacity for self-renewal, which cause the development of heterogeneous lineages during tumor formation (1-5). Assays that examine CSC activity require evaluation of the self-renewal and tumor propagation abilities of the cells (3). An increasing number of CSCs in solid tumors have been recognized through sorting cancer cells in serum-free suspension culture conditions and identifying the CSCs on the basis of differential expression of surface markers combined with in vivo propagation of tumorogenecity (6-9).

Breast cancer, the most common type of malignancy among females, has an increasing incidence, with an annual growth rate of 3\% in China, and is the primary cause of cancer-associated mortality among urban females (10). Tumorigenic breast cancer cells with stem cell properties have been isolated and identified in breast carcinoma lesions $(11,12)$. Due to the limited number of cells within the breast tumor reservoir and the location of the cells within the tumor interstitium, breast CSCs are able to develop resistance to drugs and evade chemotherapy, resulting in disease relapse, even if the primary lesion has been eradicated $(13,14)$. Therefore, investigation of novel drug resistance mechanisms that target stem cells is important to improve the current therapeutic strategies for treating breast cancer.

Octamer-binding protein 4 (Oct4) and Nanog, two of the transcriptional factors that exert key roles in the maintenance of self-renewal and pluripotency in human embryonic stem cells, have been recently observed to be expressed in numerous 
types of cancer cell line and tissue, and have been associated with aggressive tumors (15-19). Furthermore, downregulation of Oct4 and Nanog has been shown to promote stem cell differentiation and inhibit tumor development (20-22). A number of studies have revealed that Oct 4 and Nanog are detected at high levels in human breast cancer tissues, which indicates the critical roles of Oct 4 and Nanog in breast stem cell state maintenance and escape from conventional chemotherapy $(23,24)$. However, the underlying molecular mechanism by which Oct 4 and Nanog mediate the drug resistance response to chemotherapy in breast CSCs remains to be elucidated.

In the present study, breast CSCs were isolated from MDA-MB-231 breast cancer cells using a serum-free suspension culture, which characterizes the differential expression of cluster of differentiation 44 (CD44) and CD24 on the CSC cell surface combined with the capacity of CSCs to generate novel tumors when injected into a congenetic animal model. Subsequently, the differential expression of Oct 4 and Nanog mRNA in the isolated mammosphere MDA-MB-231 breast CSCs (defined as MDA-MB-231 stem cells) and the MDA-MB-231 breast cancer cells was examined. The critical relevance of Oct4 and Nanog with breast CSC therapeutic response to chemotherapy was also investigated.

\section{Materials and methods}

Ethics. This study was approved by the Institutional Ethics Committee of the First Affiliated Hospital of Xiamen University (Xiamen, China) and was in compliance with national legislation and the Declaration of Helsinki guidelines. All animal experiments were approved by the Animal Care and Use Committee of Xiamen University. Animal care was in accordance with the Regulations for the Administration of Affairs Concerning Experimental Animals of Xiamen University.

Cell lines and in vitro propagation of human breast stem cells in serum-free culture. MDA-MB-231 human breast cancer cell lines were provided by the Cancer Center of Xiamen Medical College (Xiamen, China). The cells were cultured in differentiation conditions in Dulbecco's modified Eagle's medium (DMEM) with $10 \%$ fetal bovine serum (FBS). After three days, when the cells covered $90 \%$ of the plate, adherent cells were dissociated by incubation in $0.25 \%$ trypsin-ethylenediaminetetraacetic acid solution for $1 \mathrm{~min}$ at $37^{\circ} \mathrm{C}$. MDA-MB-231 cells in the logarithmic growth phase were plated at $10^{6}, 10^{5}$, $10^{4}$ and $10^{3}$ cells/ml in serum-free DMEM/F12 (1:1) medium containing 2\% B27 (Gibco-BRL, Carlsbad, CA, USA), $20 \mathrm{ng} / \mathrm{ml}$ epidermal growth factor (EGF; Sigma-Aldrich, St. Louis, MO, USA) and $20 \mathrm{ng} / \mathrm{ml}$ basic fibroblast growth factor (bFGF; Sigma-Aldrich). The cells were cultured in these serum-free conditions as non-adherent mammosphere clusters. Differentiation was induced by culturing mammosphere cells for $12 \mathrm{~h}$ in DMEM supplemented with $10 \% \mathrm{FBS}$.

Flow cytometry. The cells were washed twice with phosphate-buffered saline (PBS) and then resuspended in the wash buffer $\left(10^{6}\right.$ cells $\left./ \mathrm{ml}\right)$. Antibodies against CD44 (fluorescein isothiocyanate-conjugated) and CD24 (phycoerythrin-conjugated) obtained from eBioscience (San Diego, CA, USA), and the corresponding isotype controls were added to the cell suspension, and the cells were incubated at $4^{\circ} \mathrm{C}$ in the dark for $40 \mathrm{~min}$. Subsequently, the cells were washed twice in $4 \mathrm{ml}$ PBS buffer and then resuspended in $400 \mu \mathrm{l}$ PBS buffer for flow cytometric analysis. The stained cells were processed using flow cytometry (BD FACSAria ${ }^{\mathrm{TM}}$ II; BD Biosciences, Franklin Lakes, NJ, USA). The results were analyzed using FlowJo v.7.6.5 software (TreeStar, Inc., Ashland, OR, USA).

Paclitaxel inhibition. Cells in a single cell suspension state were seeded in a 96-well plate at a density of $3 \times 10^{3}$ cells $/ \mathrm{ml}$ in serum-free DMEM. Subsequently, paclitaxel (Jiangsu Aosaikang Pharmaceutical Co. Ltd., Nanjing, China) was added to the suspension to bring the volume in each plate to $200 \mu \mathrm{l}$, and the paclitaxel concentrations to $0.5,1.0,2.0$, $4.0,8.0,16.0$ and $32.0 \mu \mathrm{g} / \mathrm{ml}$, respectively. The zero-adjusting well and control group were then set-up, the former without cells and the latter without paclitaxel. A volume of $20 \mu \mathrm{l}$ CellTiter-Blue ${ }^{\circledR}$ reagent (Promega Corporation, Madison, WI, USA) was added to every well after $48 \mathrm{~h}$ incubation. After $4 \mathrm{~h}$ culture at $37^{\circ} \mathrm{C}$, the optical density (OD) of each well was then measured by a fluorescence microplate reader (Beckman Institute, Urbana, IL, USA) at $570 \mathrm{~nm}$. The cell inhibition rate was defined as follows: Drug uptake percentage $=(O D$ of control group - OD of experimental group)/(OD of control group) $\mathrm{x} 100 \%$. The data were obtained from three independent experiments each performed in triplicate, in which the median inhibitory concentration $\left(\mathrm{IC}_{50}\right)$ was calculated using ProHits analysis (http://prohitsms.com/Prohits_download/list.php).

Quantitative (q)PCR. Total RNA extraction from the MDA-MB-231 cells and the MDA-MB-231 stem cells was conducted according to the TRIzol ${ }^{\circledR}$ total RNA extraction kit manufacturer's instructions. Reverse transcription was performed from 1,000 ng total RNA using the RevertAid First Strand cDNA Synthesis kit according to the manufacturer's instructions. The gene expression levels relative to those of GAPDH were assessed using qPCR with the ABI-7500 sequence detection system (Applied Biosystems, Inc., Carlsbad, CA, USA) and SYBR-Green chemistry (Shanghai Yingjun Biotechnology Limited Company, Shanghai, China), as follows: Initial denaturation at $95^{\circ} \mathrm{C}$ for $10 \mathrm{~min}$, followed by 40 cycles of denaturation at $95^{\circ} \mathrm{C}$ for $15 \mathrm{sec}$, and annealing and extension at $60^{\circ} \mathrm{C}$ for $1 \mathrm{~min}$. The human GAPDH, Oct 4 and Nanog primer sequences (Sangon Biotech, Shanghai, China) employed are shown in Table I. The reactions were run in triplicate and the generated products were analyzed with the sodium dodecyl sulfate (SDS) software (Bio-Rad Laboratories, Inc., Hercules, CA, USA). The data were evaluated as $2^{-\Delta \Delta \mathrm{Ct}}$ values ( $\mathrm{Ct}$ indicates the cycle threshold). The results are expressed as the normalization ratio of the relative quantities of the Oct4 and Nanog mRNAs to those of the control, and the fold difference to the control was used for the comparison.

Western blot analysis. The MDA-MB-231 cells and the MDA-MB-231 stem cells were collected and then lysed with radioimmunoprecipitation assay buffer and the protein concentrations within the cells were measured according to the RIPA lysate manufacturer's instructions (Applygen Technologies Inc., Beijing, China). Equivalent quantities of protein for each 
sample were separated by SDS-PAGE, transferred to PVDF membranes (Millipore, Billerica, MA, USA) and probed with the following primary antibodies: Rabbit polyclonal antibody against human OCT4 (1:8,000 dilution; cat no.: ab18976), mouse monoclonal antibody against human Nanog (1:1,000 dilution; cat no.: ab89500) and mouse monoclonal antibody against human GAPDH (1:3,000 dilution; cat no.: ab57062). All antibodies were obtained from Abcam (Cambridge, MA, USA). The PVDF membranes were incubated overnight at $4^{\circ} \mathrm{C}$ with the primary antibodies and then washed three times. A secondary horseradish peroxidase-labeled goat polyclonal antibody against rabbit (1:3,000 dilution; cat no.: ab97200) or a goat polyclonal antibody against mouse (1:4,000 dilution; cat no.: ab97265) were added and incubated for $2 \mathrm{~h}$ at room temperature. Immunodetection was performed using an electrochemiluminescent substrate (Pierce Biotechnology, Inc., Rockford, IL, USA) and the Gel Doc XR type imaging system. The intensity of bands was quantified using Image $\mathbf{J}$ software (Bio-Rad Laboratories). Three independent experiments, each in triplicate, were conducted in 24-well plates.

Silencing through RNA interference. To inhibit Oct4 or Nanog expression in the MDA-MB-231 stem cells, RNA interference silencing was performed using RNAfectin Transfection Reagent (Tiangen, Beijing, China) according to the manufacturer's instructions. All double-stranded siRNAs were designed and synthesized by Qiagen (Valencia, CA, USA). The siRNA sequences are shown in Table II.

The breast CSCs were initially plated in 24-well plates at a density of $2 \times 10^{5}$ cells/well in DMEM medium, and after $24 \mathrm{~h}$ were transfected with $7.5 \mathrm{ng} / \mu \mathrm{l}$ siRNA against Oct4, Nanog or non-targeting siRNA. Cells that had not been transfected served as controls. The cells were harvested $48 \mathrm{~h}$ after transfection to calculate the mRNA and protein expression levels.

In vivo injection of MDA-MB-231 stem cells. A total of 60 four-week-old female NOD/SCID mice with a mean body weight of $25 \pm 5 \mathrm{~g}$ were purchased from the Experimental Animal Center of Xiamen University (Xiamen, China). All mice were maintained in specific pathogen-free rooms at a certain temperature and humidity, and were provided free access to fresh water and food. A total of 40 of the NOD/SCID mice were randomly divided into eight groups by drawing lots $(n=5)$. The mice were injected subcutaneously in the right back with $0.2 \mathrm{ml}$ MDA-MB-231 cells or MDA-MB-231 stem cells at concentrations of $10^{6}, 10^{5}, 10^{4}$ and $10^{3}$ cells $/ \mathrm{ml}$. The remaining 20 mice were divided into four experimental groups $(n=5)$. The mice were injected subcutaneously in the right back with $0.2 \mathrm{ml}$ MDA-MB-231 stem cells transduced with negative interference RNA (RNAi), Oct4 RNAi and Nanog RNAi constructs at concentrations of $10^{6}$ cells $/ \mathrm{ml}$. Mice were injected subcutaneously into the right back with $0.2 \mathrm{ml}$ MDA-MB-231 stem cells without siRNA transfection, as a control group. After four weeks injection, all mice were sacrificed by cervical dislocation and tumor nodules were confirmed by necropsy. All experiments were approved by the Regional Ethical Committee for Animal Experimentation at Xiamen University.

Statistical analyses. SPSS version 16.0 (SPSS, Inc., Chicago, IL, USA) was used to analyze the data. All data are expressed as the mean values or as the percentages of control values \pm standard error of the mean depending on the experiments performed. Comparisons between two groups were calculated using Student's t-test (two-tailed, independent) and comparisons among more than two samples were analyzed using one-way analysis of variance. $\mathrm{P}<0.05$ was considered to indicate a statistically significant difference.

\section{Results}

Isolation and identification of CSCs from MDA-MB-231 breast cancer cell lines

Differential growth patterns of MDA-MB-231 breast CSCs. Human MDA-MB-231 breast cancer cells were plated into 96-cell culture dishes in DMEM medium with $10 \%$ FBS and cultured adherently (Fig. 1Aa). After $48 \mathrm{~h}$ culture in serum-free medium supplemented with B27, EGF and bFGF, the cells that were adherent to the dish died and left behind spherical clusters formed in suspension, which were subsequently defined as MDA-MB-231 stem cells (Fig. 1Ab). After $12 \mathrm{~h}$ culture in differentiating medium with $10 \%$ FBS, the floating cells were able to re-adhere and differentiate (Fig. 1Ac).

Elevated percentage of the $C D 44^{+} C D 24$-subpopulation in the mammosphere cell population. As breast cancer progenitor cells have been previously identified as $\mathrm{CD} 44^{+} \mathrm{CD} 24^{-/ \text {low }}$ cells, the cellular expression of CD44 and CD24 was evaluated by flow cytometry. The majority of the MDA-MB-231 stem cells (97.2\%) exhibited positive staining for CD44 and negative staining for CD24, which was a significantly higher percentage than that of the MDA-MB-231 cells (76.6\%; Fig. 1B).

Isolated mammosphere cell resistance to paclitaxel inhibition. The stem cell phenotype of the isolated mammosphere cells was further verified by the high resistance of the cells to chemotherapy. The result revealed cell inhibition curve of MDA-MB-231 stem cells and MDA-MB-231 cells following exposure to paclitaxel solution. The cell inhibition rate was dose-dependent. In the MDA-MB-231 stem cells, $30 \mu \mathrm{g} / \mathrm{ml}$ paclitaxel was required to reach a $100 \%$ cell inhibition rate; however, the MDA-MB-231 cells only required $15 \mu \mathrm{g} / \mathrm{ml}$ paclitaxel to reach a $100 \%$ cell inhibition rate. In the MDA-MB-231 stem cells, the paclitaxel $\mathrm{IC}_{50}$ value was almost two-fold higher than that of the MDA-MB-231 cells $(8.13 \pm 0.21$ vs. $4.17 \pm 0.20 \mu \mathrm{g} / \mathrm{ml} ; \mathrm{P}<0.05$; Fig. $1 \mathrm{C})$.

High tumor-initiating capability of isolated mammosphere cells. To compare the tumorigenicity of the MDA-MB-231 stem cells and the MDA-MB-231 breast cancer cells, the two types of cell were injected subcutaneously into NOD/SCID mice. After four weeks, MDA-MB-231 cells gave rise to novel tumors when at least $0.2 \times 10^{6}$ cells per animal were injected; however, at lower cell doses, no tumors developed. By contrast, the MDA-MB-231 stem cells formed tumors in five out of five, three out of five and one out of five animals when $0.2 \times 10^{6}$, $0.2 \times 10^{5}$ and $0.2 \times 10^{4}$ cells/animal were injected, respectively (Table III). When equal quantities $\left(0.2 \times 10^{6}\right.$ cells/animal $)$ of cells were injected, the MDA-MB-231 stem cells formed significantly bigger tumors than the MDA-MB-231 cells $(1,04$ $0.00 \pm 49.80$ vs. $146.20 \pm 16.48 \mathrm{~mm}^{3} ; \mathrm{P}<0.05$ Fig. $\left.1 \mathrm{D}\right)$.

Higher expression levels of the Oct4 and Nanog transcriptional factors in the MDA-MB-231 stem cells, as compared 
Table I. Primer sequences used in the quantitative polymerase chain reaction experiments.

\begin{tabular}{llc}
\multicolumn{1}{c}{ Gene } & \multicolumn{1}{c}{ Primer sequence (5'-3') } & size (bp) \\
\hline Oct4 & Forward: 5'-AGCAAAACCCGGAGGAGT-3' & 114 \\
& Reverse: 5'-CCACATCGGCCTGTGTATATC-3' & 124 \\
Nanog & Forward: 5'-TGAACCTCAGCTACAAACAG-3' & \\
& Reverse: 5'-TGGTGGTAGGAAGAGTAAAG-3' & 226 \\
GAPDH & Forward: 5'-GAAGGTGAAGGTCGGAGTC-3' & \\
& Reverse: 5'-GAAGATGGTGATGGGATTTC-3' \\
\hline
\end{tabular}

Oct4, octamer-binding protein 4 .

Table II. siRNA sequences used for silencing in the RNA interference experiments.

\begin{tabular}{|c|c|c|}
\hline $\begin{array}{l}\text { siRNA } \\
\text { target gene }\end{array}$ & Primer sequence $\left(5^{\prime}-3^{\prime}\right)$ & $\begin{array}{l}\text { Molecular } \\
\text { weight }\end{array}$ \\
\hline Oct 4 & $\begin{array}{ll}\text { Forward } & \text { 5'-GGAUUAAGUUCUUCAUUCATT-3' } \\
\text { Reverse } & \text { 5'-UGAAUGAAGAACUUAAUCCCA-3' }\end{array}$ & $\begin{array}{l}21 \mathrm{bp} / 4943.32 \\
21 \mathrm{bp} / 5540.69\end{array}$ \\
\hline Nanog & $\begin{array}{l}\text { Forward 5'-UGAUUGUUCCAGGAUUGGGTG-3' } \\
\text { Reverse 5'-CACCCAATCCTGGAACAATCA-3' }\end{array}$ & $\begin{array}{l}21 \mathrm{bp} / 5257.49 \\
21 \mathrm{bp} / 6407.11\end{array}$ \\
\hline
\end{tabular}

siRNA, small interfering RNA; Oct4, octamer-binding protein 4.

with the MDA-MB-231 cells. The MDA-MB-231 stem cells exhibited significantly higher relative mRNA and protein expression levels of the Oct4 and Nanog putative stem cell markers than the MDA-MB-231 cells $(\mathrm{P}<0.05)$, which was further confirmed by real-time PCR (Fig. 2A) and western blot analysis (Fig. 2B).

Reduced MDA-MB-231 stem cell drug resistance to paclitaxel following downregulation of Oct4 and Nanog

Expression levels of Oct4 and Nanog $m R N A$ are reduced when either Oct4 or Nanog is knocked-down. Oct4 and Nanog mRNA and protein downregulation following transfection of MDA-MB-231 stem cells with the respective RNAi molecules were analyzed by qPCR and western blot analysis, respectively. shRNA transduction of Oct4 constructs not only significantly reduced Oct 4 mRNA but also significantly downregulated Nanog transcripts in the MDA-MB-231 stem cells $(\mathrm{P}<0.05$; Fig. 3Aa). Similarly, the MDA-MB-231 stem cells transfected with the Nanog RNAi constructs exhibited significantly reduced the expression levels of Nanog mRNA and significantly downregulated Oct4 mRNA ( $\mathrm{P}<0.05$; Fig. 3Ab). The results were consistent with the data concerning the respective protein molecules in the western blot analysis (all $\mathrm{P}<0.05$; Fig. 3B).

Reduced drug resistance and tumor-initiating capability of mammoshere cells following downregulation of Oct4 and Nanog. The MDA-MB-231 stem cells transfected with Oct4 or Nanog RNAi constructs became more sensitive to paclitaxel inhibition. The data revealed paclitaxel inhibition curves for MDA-MB-231 stem cells or MDA-MB-231 stem cells transduced with negative RNAi, Oct4 RNAi and Nanog RNAi constructs (Fig. 3C). In the MDA-MB-231 stem cells transfected with the Oct4 RNAi constructs, the $\mathrm{IC}_{50}$ values were almost two-fold lower than those of cells transfected with negative RNAi $(4.49 \pm 0.10$ vs. $8.30 \pm 0.39 \mu \mathrm{g} / \mathrm{ml}$; $\mathrm{P}<0.05)$. The MDA-MB-231 stem cells transfected with Nanog RNAi constructs also exhibited reduced $\mathrm{IC}_{50}$ values, as compared with the cells transfected with negative RNAi (5.17 \pm 0.12 vs. $8.30 \pm 0.39 \mu \mathrm{g} / \mathrm{ml}$; Fig. 3C). Therefore, the data demonstrated that downregulation of Oct4 or Nanog enhanced the sensitivity of human breast CSCs to drug chemotherapy. Furthermore, the tumorigenicity of the MDA-MB-231 stem cells transfected with Oct4 RNAi or Nanog RNAi was reduced. When injecting equal quantities of cells, the Oct4 RNAi and Nanog RNAi groups formed significantly smaller tumors than either the negative RNAi or control group $(1,163.00 \pm 33.80$ and $1,108.00 \pm 24.93 \mathrm{~m}$ $\mathrm{m}^{3}$ vs. $210.80 \pm 16.60$ and $167.80 \pm 17.76 \mathrm{~mm}^{3}$; $\mathrm{P}<0.05$; Fig. 3D).

\section{Discussion}

Breast cancer is currently the most frequently occurring type of cancer and the primary cause of cancer-related mortality in females worldwide (10). With increasing advances in the investigation of CSCs, breast CSCs have been gradually determined to be capable of self-renewal and maintaining tumor growth and heterogeneity, as well as being rare, rendering these cells a promising foundation for stem cell-based therapeutics (25-28). Therefore, the identification of pure breast CSCs is key for the development of targeted antitumor therapies. In the present study, mammospheres were observed to form in serum-free 
A
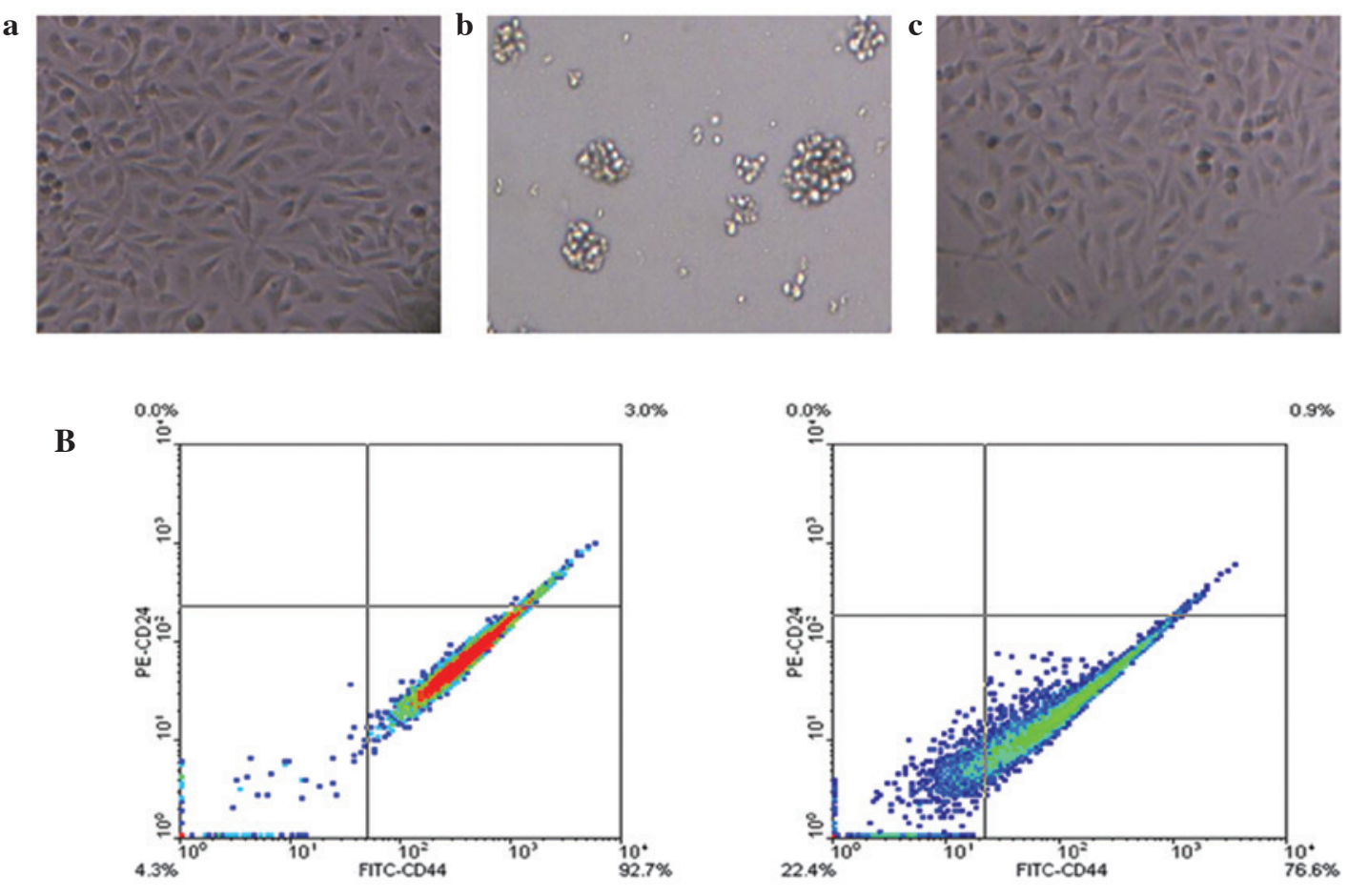

MDA-MB-231 stem cells
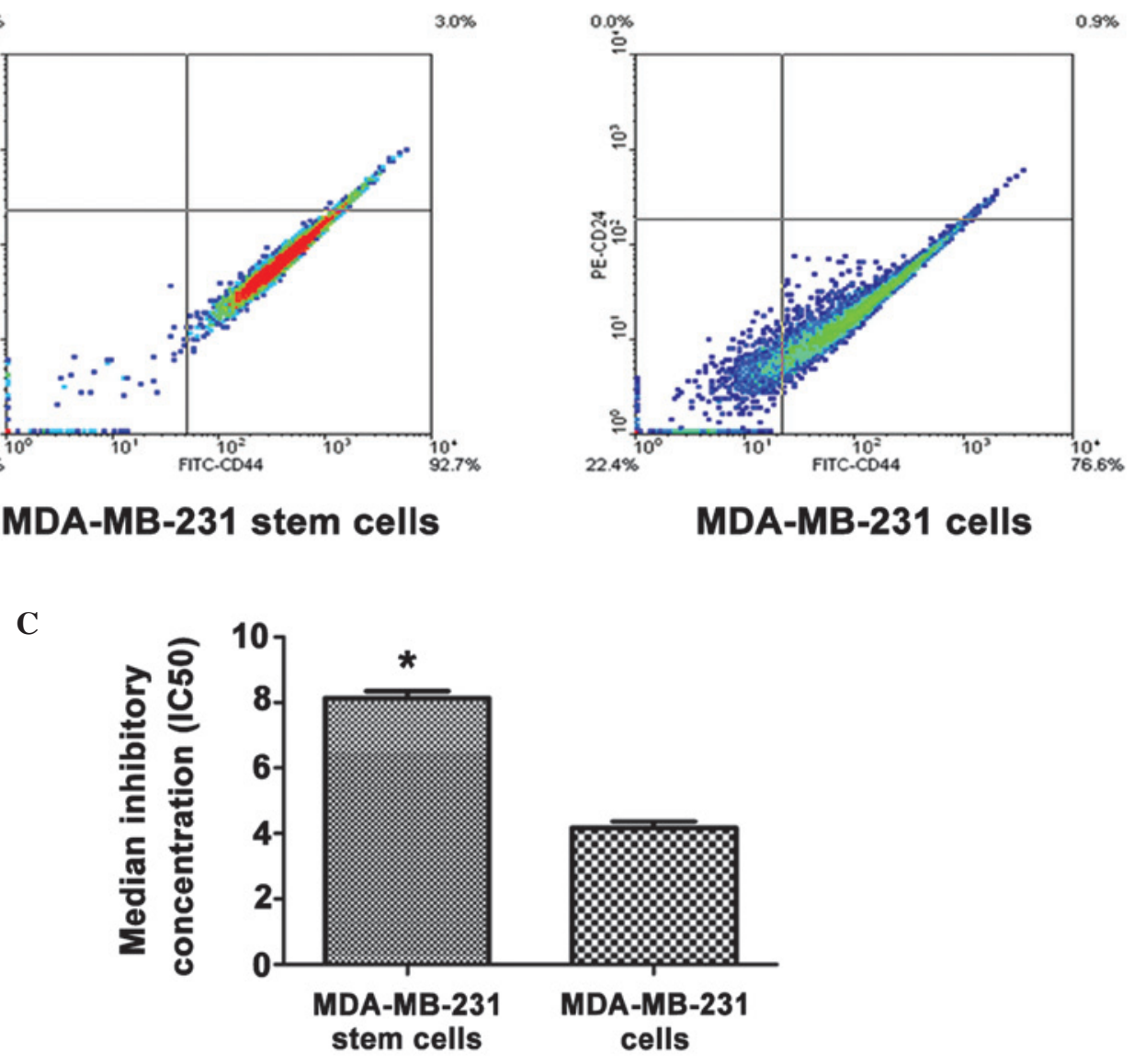

D
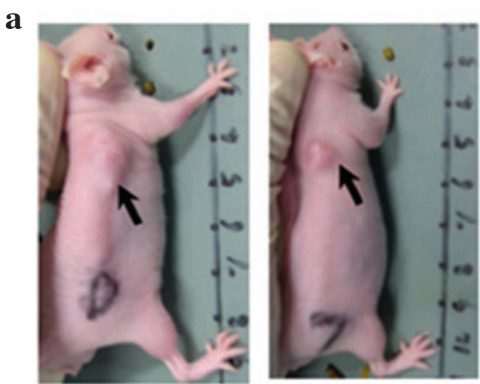

MDA-MB-231 MDA-MB-231

stem cells cells b

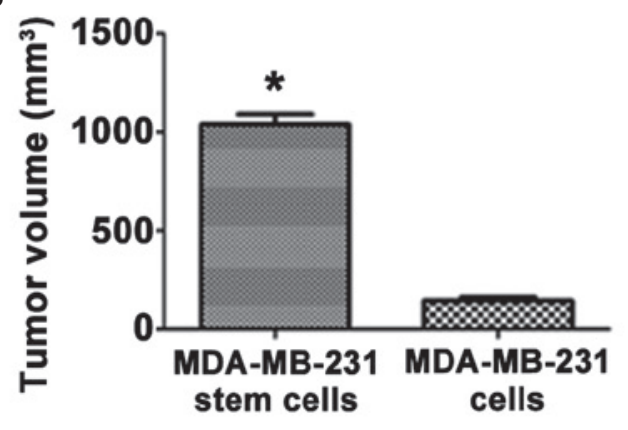

Figure 1. Isolation and identification of cancer stem cells from MDA-MB-231 breast cancer cell lines. (A) Culture of (Aa) MDA-MB-231 cells in medium with $10 \%$ fetal bovine serum (FBS), (Ab) MDA-MB-231 stem cells in serum-free medium and (Ac) MDA-MB-231 stem cells in medium with $10 \%$ FBS (B) Fluorescence-activated cell sorter analysis of cluster of differentiation 44 (CD44)/CD24 expression in MDA-MB-231 breast cancer cell lines cultured in serum-free medium (MDA-MB-231 stem cells) and in medium with 10\% FBS (MDA-MB-231 cells). The majority of MDA-MB-231 stem cells (97.2\%) exhibited positive CD44 staining and negative CD24 staining, which was significantly higher than the percentage of MDA-MB-231 breast cancer cells (76.6\%) with the corresponding staining pattern. The analysis was repeated three times. (C) Cell inhibition curves of the median inhibitory concentration (IC) of paclitaxel following the incubation of MDA-MB-231 stem cells and MDA-MB-231 cells with paclitaxel solution. The data are representative of three independent experiments (means \pm standard error of the mean). "P<0.05, as compared with the MDA-MB-231 cells. (D) Tumor xenografts in mice. (Da) The arrows indicate visible tumors induced by MDA-MB-231 stem cells and MDA-MB-231 cells, respectively. (Db) The volume difference of tumors induced by MDA-MB-231 stem cells and those induced by MDA-MB-231 cells. "P<0.05 compared with the MDA-MB-231 cells ( $\mathrm{n}=5)$. 


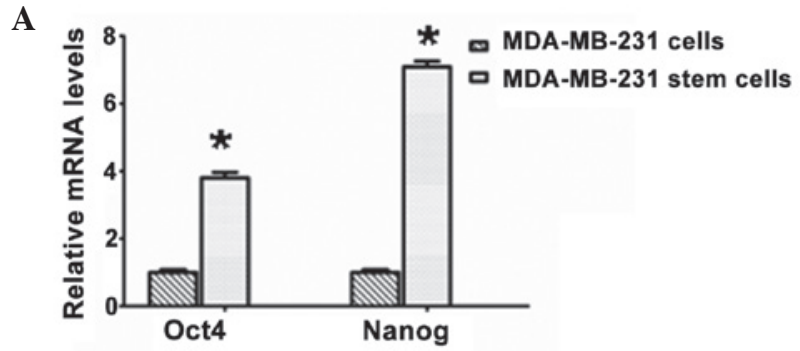

B
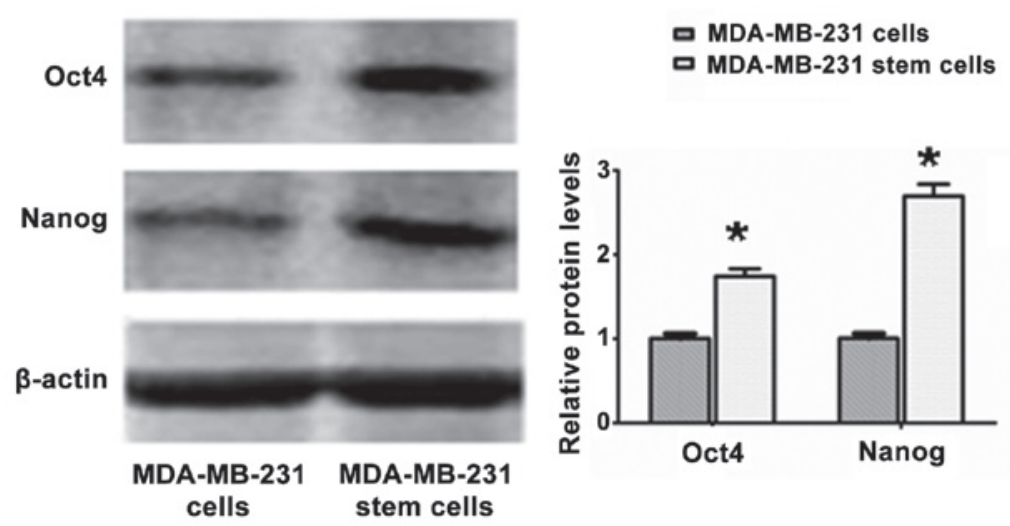

Figure 2. Expression levels of the octamer-binding protein 4 (Oct4) and Nanog transcriptional factors in MDA-MB-231 breast cancer stem cells. (A) Quantitative polymerase chain reaction reveals the relative expression levels of Oct4 and Nanog in MDA-MB-231 cells and MDA-MB-231 stem cells. (B) The protein expression levels of Oct4 and Nanog were determined by western blot analysis. Data are representative of three independent experiments (mean \pm standard error of the mean). ${ }^{*} \mathrm{P}<0.05$ compared with the MDA-MB-231 cells.

Table III. Tumor-initiating capability of isolated MDA-MB-231 stem cells and MDA-MB-231 cells.

\begin{tabular}{lcc}
\hline & \multicolumn{2}{c}{ Tumorigenicity } \\
\cline { 2 - 3 } $\begin{array}{l}\text { Cells/ } \\
\text { animal }\end{array}$ & $\begin{array}{c}\text { MDA-MB-231 } \\
\text { stem cells }\end{array}$ & $\begin{array}{c}\text { MDA-MB-231 } \\
\text { cells }\end{array}$ \\
\hline $0.2 \times 10^{6}$ & $5 / 5$ & $3 / 5$ \\
$0.2 \times 10^{5}$ & $3 / 5$ & $0 / 5$ \\
$0.2 \times 10^{4}$ & $1 / 5$ & $0 / 5$ \\
$0.2 \times 10^{3}$ & $0 / 5$ & $0 / 5$ \\
\hline
\end{tabular}

medium in the presence of B27, EGF and bFGF, and with sustained long-term suspension culture. In medium with the addition of $10 \%$ FBS, mammosphere cells are able to differentiate into numerous cell types in vitro. The results from the present study support the CSC hypothesis that stem cells in culture are characterized by a self-renewing and proliferation ability upon appropriate stimulation, as well as by an undifferentiated status and the capacity to differentiate into heterogeneous mature cell types, results comparable with those observed by Li et al (27). Even through breast CSCs have been reported to be $\mathrm{CD} 44^{+} / \mathrm{CD} 24^{- \text {low }}$ cells, it is not sufficient to define a stem cell solely on its surface markers $(8,9,29)$. In the present study, mammosphere cells were demonstrated to predominantly consist of the CD $44^{+} \mathrm{CD} 24^{- \text {llow }}$ subpopulation. However, MDA-MB-231 breast cancer cells also had $76.6 \% \mathrm{CD} 44^{+} \mathrm{CD} 24^{- \text {llow }}$ cells, indicating that the $\mathrm{CD} 44^{+} \mathrm{CD} 24^{-/ \text {low }}$ subpopulation may encompass stem cells with self-renewal and other cell types without this property (29). Furthermore, the isolated mammosphere cells were also revealed to be more tumorigenic in vivo and more refractory to chemotherapy than the original MDA-MB-231 breast cancer cells, which was consistent with the results of previous studies $(12,25,27)$. These data revealed that the isolated mammosphere cells were true breast CSCs, thus the cells were termed MDA-MB-231 stem cells.

In recent years, increasing evidence has emerged that CSCs exert an important role in drug resistance, tumor relapse and cancer metastasis in various types of cancer, including breast cancer $(13,14)$. Major factors that affect drug sensitivity include drug-associated gene variation, the expression of the ATP binding cassette family of membrane transport proteins and the expression of antiapoptotic genes (30-33). Oct4 and Nanog are core transcriptional factors within the regulatory network required for the maintenance of self-renewal and pluripotency in embryonic stem cells, and any upregulation or downregulation induces divergent cell fates (22). Either Oct4 or Nanog depletion may result in the differentiation of normal human pluripotent stem cell cultures (34). Previous studies have observed that Oct4 and Nanog are overexpressed among numerous malignant solid tumor types that are immortal, undifferentiated and invasive $(19,23)$. Knockdown of the two factors may inhibit tumor development and growth $(20,22)$. Thus, Oct4 and Nanog may serve as a regulatory code for the response of breast CSCs to drug therapy. In concurrence with the results of previous studies $(23,24)$, the MDA-MB-231 stem cells in the present study exhibited relatively high expression levels of the Oct 4 and Nanog. Furthermore, the $\mathrm{IC}_{50}$ values were shown to be almost two-fold lower than those of the controls 
A

a

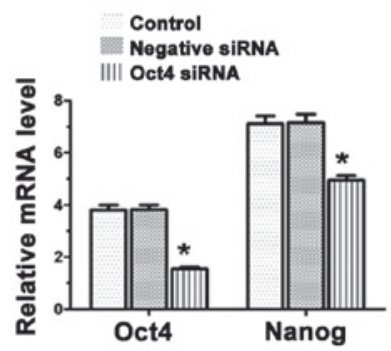

B

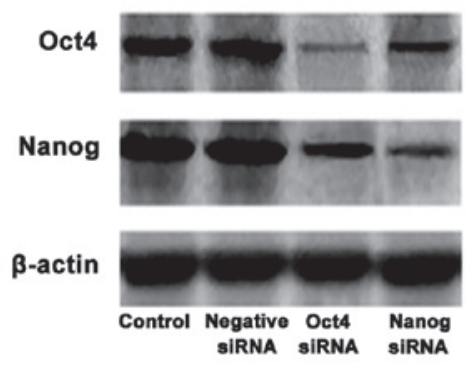

b
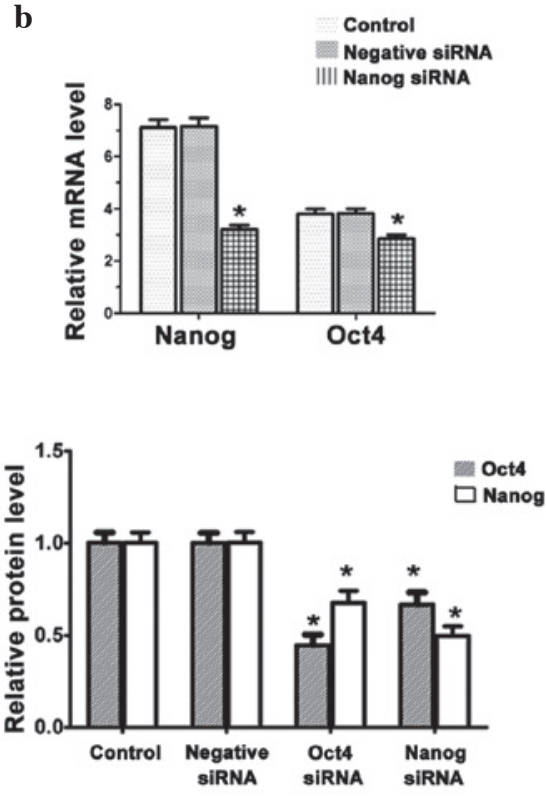

C

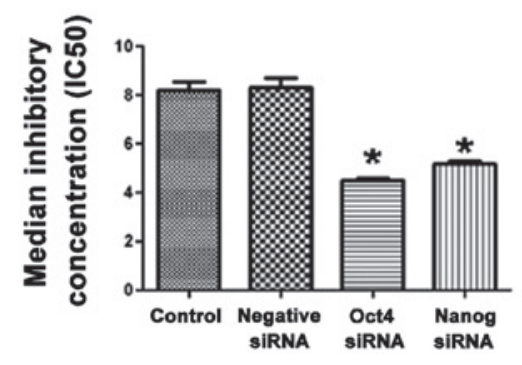

D

a

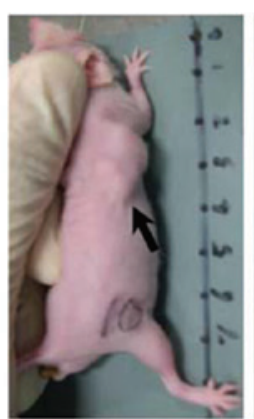

Control

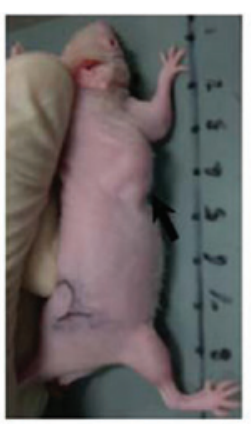

Negative siRNA

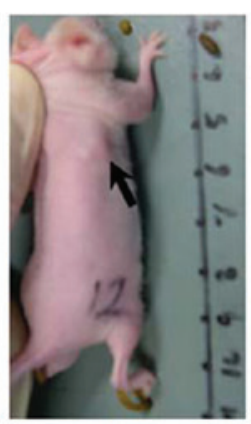

Oct4 siRnA

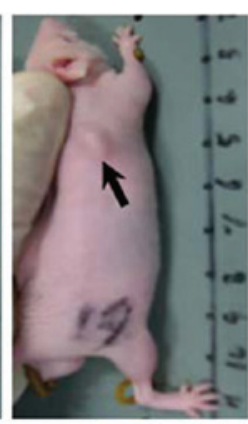

Nanog siRNA

b

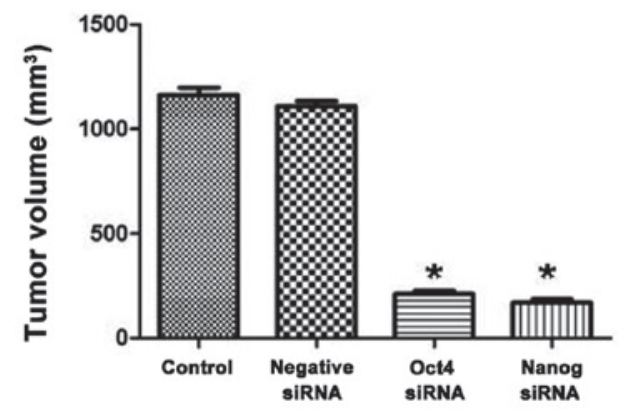

Figure 3. (A) Efficacy and the specificity of targeted small interfering (si)RNA silencing of (Aa) octamer-binding protein 4 (Oct4) and (Ab) Nanog gene expression analyzed by real-time polymerase chain reaction (PCR) analysis $48 \mathrm{~h}$ after siRNA transfection of MDA-MB-231 breast cancer stem cells. (B) The protein expression levels of Oct4 and Nanog following siRNA transfection of the MDA-MB-231 stem cells were determined by western blot analysis. (C) Paclitaxel cell inhibition curves following MDA-MB-231 stem cell transfection with negative siRNA, Oct4 siRNA or Nanog siRNA, and subsequent incubation with paclitaxel solution. The data are representative of three independent experiments (means \pm standard error of the mean). " $\mathrm{P}<0.05$, as compared with the control and negative siRNA. (D) Reduced tumor-initiating capability of MDA-MB-231 stem cells following downregulation of Oct4 or Nanog in mice. (Da) The arrows indicate visible tumors induced by MDA-MB-231 stem cells transfected with negative siRNA, Oct4 siRNA or Nanog siRNA. (Db) The difference in volume of tumors induced by MDA-MB-231 stem cells transfected with different siRNAs. ${ }^{*} \mathrm{P}<0.05$ compared with the negative RNAi and control groups. 
when the MDA-MB-231 stem cells were transfected with Oct4 RNAi constructs. MDA-MB-231 stem cells transfected with Nanog RNAi constructs also exhibited reduced IC $_{50}$ values as compared with the controls, demonstrating that downregulation of Oct4 or Nanog enhanced the sensitivity of the human breast CSCs to drug chemotherapy. Furthermore, when injecting equal quantities of cells into mice, the MDA-MB-231 stem cells transfected with Oct4 RNAi or Nanog RNAi formed significantly $(\mathrm{P}<0.05)$ smaller tumors than the negative RNAi or control group cells, demonstrating that the downregulation of Oct4 or Nanog reduced the tumorigenicity in breast CSCs. Therefore, the present study indicated that Oct4 or Nanog-targeted therapy may be a promising means of overcoming resistance to chemotherapy and inhibiting tumor growth in breast cancer.

In conclusion, breast CSCs were isolated by suspension culture in serum-free medium and human breast CSCs were characterized with elevated percentages of the $\mathrm{CD} 44^{+} \mathrm{CD} 24^{-/ \text {low }}$ subset, high tumorigenicity and resistance to chemotherapy, which encompassed stem cell-like properties. Furthermore, breast CSCs also expressed high levels of the Oct4 and Nanog transcriptional factors. To the best of our knowledge, the present study revealed for the first time the key role of Oct4 and Nanog in chemotherapeutic resistance and tumor growth in breast CSCs, which provides a possible novel insight into stem cell-based target therapies in breast cancer.

\section{Acknowledgements}

This study was supported by the Key Projects of Fujian Province Technology (grant no. 2010D026), the Medical Innovations Topic in Fujian Province (grant no. 2012-CXB-29) and the Projects of Xiamen scientific and technological plan (grant nos. 3502Z20134011 and 3502Z20124018). This study was performed in Xiamen University (Xiamen, China).

\section{References}

1. Odorico JS, Kaufman DS and Thomson JA: Multilineage differentiation from human embryonic stem cell lines. Stem Cells 19: 193-204, 2001.

2. Romano G: The role of adult stem cells in carcinogenesis. Drug News Perspect 18: 555-559, 2005.

3. Clarke MF, Dick JE, Dirks PB, et al: Cancer stem cells - perspectives on current status and future directions: AACR Workshop on cancer stem cells. Cancer Res 66: 9339-9344, 2006.

4. Guo W, Lasky JL and Wu H: Cancer stem cells. Pediatr Res 59: 59R-64R, 2006.

5. Dalerba P, Cho RW and Clarke MF: Cancer stem cells: Models and concepts. Annu Rev Med 58: 267-284, 2007.

6. Gibbs CP, Kukekov VG, Reith JD, et al: Stem-like cells in bone sarcomas: Implications for tumorigenesis. Neoplasia 7: 967-976, 2005.

7. Wilson H, Huelsmeyer M, Chun R, Young KM, Friedrichs K and Argyle DJ: Isolation and characterisation of cancer stem cells from canine osteosarcoma. Vet J 175: 69-75, 2008.

8. Bhat-Nakshatri P, Appaiah H, Ballas C, et al: SLUG/SNAI2 and tumor necrosis factor generate breast cells with $\mathrm{CD} 44^{+} / \mathrm{CD} 24$ phenotype. BMC Cancer 10: 411, 2010.

9. Sheridan C, Kishimoto H, Fuchs RK, et al: CD44+CD24- breast cancer cells exhibit enhanced invasive properties: an early step necessary for metastasis. Breast Cancer Res 8: R59, 2006.
10. DeSantis C, Siegel R, Bandi P and Jemal A: Breast cancer statistics, 2011. CA Cancer J Clin 61: 409-418, 2011.

11. Al-Hajj M, Wicha MS, Benito-Hernandez A, Morrison SJ and Clarke MF: Prospective identification of tumorigenic breast cancer cells. Proc Natl Acad Sci USA 100: 3983-3988, 2003.

12. Ponti D, Costa A, Zaffaroni N, et al: Isolation and in vitro propagation of tumorigenic breast cancer cells with stem/progenitor cell properties. Cancer Res 65: 5506-5511, 2005.

13. Dean M, Fojo T and Bates S: Tumour stem cells and drug resistance. Nat Rev Cancer 5: 275-284, 2005.

14. Donnenberg VS and Donnenberg AD: Multiple drug resistance in cancer revisited: The cancer stem cell hypothesis. J Clin Pharmacol 45: 872-877, 2005.

15. Campbell PA, Perez-Iratxeta C, Andrade-Navarro MA and Rudnicki MA: Oct4 targets regulatory nodes to modulate stem cell function. PLoS One 2: e553, 2007.

16. Tai MH, Chang CC, Kiupel M, Webster JD, Olson LK and Trosko JE: Oct4 expression in adult human stem cells: evidence in support of the stem cell theory of carcinogenesis. Carcinogenesis 26: 495-502, 2005.

17. Mitsui K, Tokuzawa Y, Itoh H, et al: The homeoprotein Nanog is required for maintenance of pluripotency in mouse epiblast and ES cells. Cell 113: 631-642, 2003.

18. Jeter CR, Badeaux M, Choy G, et al: Functional evidence that the self-renewal gene NANOG regulates human tumor development. Stem Cells 27: 993-1005, 2009.

19. Chang CC, Shieh GS, Wu P, Lin CC, Shiau AL and Wu CL: Oct-3/4 expression reflects tumor progression and regulates motility of bladder cancer cells. Cancer Res 68: 6281-6291, 2008.

20. Velkey JM and O'Shea KS: Oct4 RNA interference induces trophectoderm differentiation in mouse embryonic stem cells. Genesis 37: 18-24, 2003.

21. Gidekel S, Pizov G, Bergman Y and Pikarsky E: Oct-3/4 is a dose-dependent oncogenic fate determinant. Cancer Cell 4: 361-370, 2003

22. Boyer LA, Lee TI, Cole MF, et al: Core transcriptional regulatory circuitry in human embryonic stem cells. Cell 122: 947-956, 2005.

23. Ezeh UI, Turek PJ, Reijo RA and Clark AT: Human embryonic stem cell genes OCT4, NANOG, STELLAR, and GDF3 are expressed in both seminoma and breast carcinoma. Cancer 104: 2255-2265, 2005.

24. Liu C, Lu Y, Wang B, et al: Clinical implications of stem cell gene Oct-4 expression in breast cancer. Ann Surg 253: 1165-1171, 2011.

25. Dontu G, Abdallah WM, Foley JM, et al: In vitro propagation and transcriptional profiling of human mammary stem/progenitor cells. Genes Dev 17: 1253-1270, 2003.

26. Dontu G and Wicha MS: Survival of mammary stem cells in suspension culture: Implications for stem cell biology and neoplasia. J Mammary Gland Biol Neoplasia 10: 75-86, 2005.

27. Li HZ, Yi TB and Wu ZY: Suspension culture combined with anticancer regimens for screening breast cancer stem cells. Med Hypotheses 68: 988-990, 2007.

28. Sell S: Stem cell origin of cancer and differentiation therapy. Crit Rev Oncol Hematol 51: 1-28, 2004.

29. Abraham BK, Fritz P, McClellan M, Hauptvogel P, Athelogou $\mathrm{M}$ and Brauch $\mathrm{H}$ : Prevalence of CD $44^{+} / \mathrm{CD} 24^{-1}$ ${ }^{\text {low }}$ cells in breast cancer may not be associated with clinical outcome but may favor distant metastasis. Clin Cancer Res 11: 1154-1159, 2005.

30. Gottesman MM, Fojo T and Bates SE: Multidrug resistance in cancer: role of ATP-dependent transporters. Nat Rev Cancer 2: 48-58, 2002.

31. Schinkel AH and Jonker JW: Mammalian drug efflux transporters of the ATP binding cassette (ABC) family: an overview. Adv Drug Deliv Rev 55: 3-29, 2003.

32. Szakács G, Annereau JP, Lababidi S, et al: Predicting drug sensitivity and resistance: profiling $\mathrm{ABC}$ transporter genes in cancer cells. Cancer Cell 6: 129-137, 2004.

33. Gottesman MM, Ludwig J, Xia D and Szakács G: Defeating drug resistance in cancer. Discov Med 6: 18-23, 2006.

34. Ji J, Werbowetski-Ogilvie TE, Zhong B, Hong SH and Bhatia M: Pluripotent transcription factors possess distinct roles in normal versus transformed human stem cells. PLoS One 4: e8065, 2009. 